\title{
Care Coordination in Bone Health Screening Between Individual Behaviors and Health Care Services Among Korean-American Women Across Three Age Groups
}

Asian/Pacific Island Nursing Journal

Volume 1(4): 174-182

(c)Author(s) 2016

http://digitalscholarship.unlv.edu/apin/

\author{
Young-Shin Lee ${ }^{\mathrm{a}}$
}

\begin{abstract}
Integrated continuous care is important to prevent and treat brittle bone status in the aging process; however, minority groups often have limited access to health services. The purpose of this study was to identify the care coordination among women's perceptions about their bone health, information from health care providers, and the results of Bone Mineral Density (BMD) tests across three age groups. The study was a cross-sectional comparative design. A total of 63 Korean American women completed both the assessment of BMD of the femoral neck and an interview survey. One's own risks of osteoporosis, screening behaviors, and health care providers' advice were analyzed according to three age (pre-, peri-, and post-menopausal) groups, BMD levels, and health insurance coverage. Overall, health insurance coverage and having a primary health care provider of Korean American women were $59.0 \%$ and $32.0 \%$, respectively; $61.9 \%$ had lower than normal BMD levels, which were significantly increased by advanced age. Individual awareness of risks of osteoporosis and screening behaviors were significantly higher in peri-menopausal than in pre- and post-menopausal groups, but no differences were found in health care providers' information. The awareness and care providers' information by BMD level or health insurance did not differ. The findings show a discrepancy between individual perceptions and behaviors and health care providers' recommendations regard to bone health. Health behaviors should be guided by professional health care providers. The women in the post-menopausal stage need to be educated about the high risk of osteoporosis and its management.
\end{abstract}

Keywords: osteoporosis, awareness, health care services, bone mineral density (DXA)

Access to health care services is a leading health indicator of Healthy People 2020 in the United States (U.S. Department of Health and Human Services, 2015). In 2012, 83.1\% of adults under age 65 years were covered by health insurance and $77 \%$ had a primary care provider. A primary care provider is defined as a medically trained nurse or physician who is licensed to take care of patients' basic health needs and coordinates a patient access to a range of health care services (Centers for Medicare \& Medicaid Services, 2016; U.S. Department of Health and Human Services, 2015). For Asians, the access to care services was 20\% lower than the whites' group (Agency for Healthcare Research and Quality, 2011). Limited ac- cess to health care may cause obstacles to maximal utilization of individual capability for prevention and management of disease (U.S. Department of Health and Human Services, 2014). Many patients seek solutions only for single health problems rather than receiving regular screenings and coordinated care for their overall health condition(s) (U.S. Department of Health and Human Services, 2014).

\footnotetext{
Corresponding Author:

Young-Shin Lee, PhD, RN

San Diego State University

School of Nursing

Email: ylee@mail.sdsu.edu
}

${ }^{a}$ San Diego State University, San Diego, CA, USA 
Osteoporosis, or having porous bones, is a disease characterized by low bone mass, too little bone formation, and/or excessive bone loss, leading to bone fragility and an increased risk of fractures. It is a serious, common, debilitating disease and a major public health problem for older adults (National Institutes of Health, 2015). Osteoporosis is associated with aging due to a high risk of falls and injuries (U.S. Department of Health and Human Services, 2004). In 2010, $10.3 \%$ of U.S. adults aged 50 years or older had osteoporosis and $43.9 \%$ had low bone mass. The prevalence increased noticeably with age, being 10 times greater among women aged 85+ than those aged 65 (He, Sengupta, Velkoff, \& DeBarros, 2005). Even though bone density and bone strength become weak due to the aging process, they can be prevented and treated. Public awareness about bone health is not substantial enough to prevent and treat these bone conditions (U.S. Department of Health and Human Services, 2015; World Health Organization, 2004).

Bone conditions of women after menopause may deteriorate dramatically due to hormonal changes (U.S. Department of Health and Human Services, 2004; World Health Organization, 2004). Asian women's bone density has been reported to be lower than any other ethnic group. Studies indicate that Asian women have twice the prevalence rate of osteoporosis as compared with the African American population and a higher prevalence of vertebral fractures than Caucasians (Chen, Warner, Fingerhut, \& Makuc, 2009; U.S. Department of Health and Human Services, 2015). Korean Americans are among the five largest Asian-American groups in the United States (U.S. Census Bureau, 2012), but this group's bone conditions and their health care coverage were rarely reflected as a single ethnic group in previous bone health research.

The current study was designed based on Anderson's Behavioral Model of Health Services Use, which focused on the association of individual units, health care utilization, and outcomes (Andersen, 1995; Anderson, 2008). The model constructs and conceptualizes population characteristics (i.e., demographics, health insurance, primary care providers, and perceived needs), health behaviors (i.e., personal health practices and use of health services), and health outcomes. The model proposes that effective access to health care services would improve health status and satisfaction as well as patient perception. The health care system and external environment affect health perception and health status, which again impact the previous steps (personal characteristics, practices, etc.; Andersen, 1995). The Behavioral Model of Health Services Use has been used widely to explain the use of health care services and health behaviors related to health problems (Babitsch, Gohl, \& von Lengerke,
2012; Lee \& Jang, 2016; Lee et al., 2012). The current study hypothesized that individual perception and screening behaviors regarding osteoporosis would be associated with their bone status (as a health outcome) as well as the use of health care services.

The purpose was to identify the association between individual perceptions and behaviors in bone health and health care services among Korean-American (KA) women living in the United States. Specific aims included identifying the following:

1. Awareness of one's own risks regarding bone health, history of bone screening, and information regarding bone health from health care providers (HCP) by age groups (Pre, Peri, and Post-menopause)

2. Consistency in health care in terms of individual awareness, behaviors by bone mineral density (BMD) status, and information provided by health care systems (e.g., health insurance and primary care providers)

\section{Method}

\section{Design and Settings}

This pilot study was a cross-sectional descriptive design with a stratified sampling method. After approval of the institutional review board for human research from the university, participants were recruited from the KA community (KA churches, KA health clinics, and other KA Associations) with flyers and contact information in both Korean and English. KA women who showed an interest were introduced to the following research issues by phone: Purpose, process, inclusion and exclusion criteria, confidentiality, and usage of findings. If the KA women were eligible for the study and agreed to participate, they were invited to the research center by a letter. At the center, each person was given a consent form and had it explained to her. After the written consent form was completed, the survey and exam initiated the beginning steps of the study.

The inclusion criteria included (a) belonging to one of three age groups (25-35 years, 45-55 years, and 65+), (b) self-reported Korean women descended from Korean parents, (c) living independently in the community, and (d) availability to come to the research center for an evaluation by dual-energy X-ray absorptiometry (DXA) scan. Their ages were categorized into three groups by the status of bone formation and rebuilding (National Institutes of Health 2015; U.S. Department of Health and Human Services, 2004): Pre-menopause (Pre-M) group (aged 25-35 years), Peri-menopause (Peri-M; aged 45-55 years) 
and transient status to menopause, and Post-menopause (Post-M; aged 65+ years). The age classification was based on the following: Bone changes in size, shape and position by modeling and remodeling throughout life. Bone modeling reaches its peak by the early 20 s and then declines slowly; early menopause starts by age 45 years with a median age of approximately 51 years. After menopause, the annual bone loss is significant for five years and then stabilizes (Cramer \& Xu, 1996; Mazzuoli et al, 2000; U.S. DHHS, 2004). Those who had a history or evidence of metabolic disease (i.e., hyper or hypoparathyroidism, Paget's disease, osteomalacia, renal osteodystrophy or osteogenesis imperfecta), bone cancer, ovary removal (oophorectomy), broken bones on hip(s), or unusual irregular menstrual cycles among those aged 25-35 years old were excluded.

A total of $63 \mathrm{KA}$ women (20 to 22 in each age group) living in Southern California completed the BMD screening and face-to-face interviews by bilingual persons. No compensation except BMD test results and reports was provided. Regarding sample size, a sample size in a pilot study ranging 10-40 per group is considered adequate enough to estimate a variety of possible aims (Hertzog, 2008).

\section{Measures}

Demographic information including age, family income, marital status, living alone or with others, employment, health insurance, and the presence or absence of a primary HCP was collected. Age was defined by date of birth for all three groups. Annual family income was categorized into three groups: (a) lower than $\$ 30,000$; (b) $\$ 30,000$ to less than $\$ 60,000$; and (c) $\$ 60,000$ or higher, which exceeded the federal poverty level of family income by $150 \%$ and $300 \%$, respectively. Current marital status, living alone or together with others, having health insurance, and having a usual primary HCP were dichotomized as "yes" or "no." Pre-M and Post-M groups were identified by ages 25-35 and 65+, respectively; those aged 45-55 years and had no menstrual bleeding in three months, and irregular or cessation of menstruation in a year comprised the Peri-M group.

Regarding perceptions of risks about their own osteoporosis, participants were asked the following questions: "Do you think you have a risk of developing osteoporosis?" with five choices from very low to very high, with a higher score meaning a higher risk of osteoporosis. The answers were combined and dichotomized as high versus not high. In order to assess the HCP's advice, two questions were asked: (a)
"Have you heard that you have 'brittle bones' or osteoporosis?" and (b) "Has a doctor or health care provider ever told you to obtain screening for your bone health?" Bone screening history was identified by asking "Have you ever obtained screening for your bone status?"

BMD at the femoral neck site was assessed by a DXA scan using a Lunar Prodigy Advance densitometer (GE/Lunar Corp, Madison, WI). The results of the DXA were classified into three groups: Normal was represented by a T-score of $-1.0 \mathrm{SD}$ or higher, Low bone mass by a T-score of BMD between -1.0 and -2.5 $S D$, and Osteoporosis as a T-score of BMD -2.5 SD or lower (Kanis et al., 2008; World Health Organization, 1994).

\section{Analysis}

All the data were cleaned and categorized regarding the variables of age, BMD status, and awareness of the risk of osteoporosis. A descriptive analysis was done in all variables. For each research objective, cross tabulation analysis was applied to yield Pearson's Chi-square values; when a cell contained smaller than five samples and those cells were more than $20 \%$, Fisher's Exact Test value was calculated with a significance level of .05. The data obtained through interview processes had no missing data.

\section{Results}

A total of $63 \mathrm{KA}$ women participated in the study. With regard to demographic information, there were significant differences in marital status, family income, employment status, living status, and health insurance coverage by the menopausal status of PreM, Peri-M, and Post-M groups (Table 1). Sixty-two of 63 were born in Korea and currently reside in Southern California. Among the participants, more than $50.0 \%$ overall and $85.7 \%$ of Post-M group had a family income less than $\$ 30,000\left(\chi^{2}=15.46, p=.004\right) ; 28.6 \%$ of the Post-M group lived alone $\left(\chi^{2}=9.99, p=.007\right)$. Regarding health insurance, $58.7 \%$ in the Pre-M group were covered with health insurance and $40.9 \%$ and $81.0 \%$ in Peri-M and Post-M groups, respectively $\left(\chi^{2}\right.$ $=7.28, p=.026$ ). Overall, $31.7 \%$ of KA women had a primary HCP; there were no group differences in having a $\operatorname{HCP}\left(\chi^{2}=1.31, p=.518\right)$.

\section{Awareness of Risks of Developing Osteopo- rosis}

In terms of awareness of bone health, overall $34.9 \%$ of KA women reported they had a high risk of 
osteoporosis; the same was true for $59.1 \%$ of Peri-M and $19.0 \%$ of Post-M groups, which were significantly different by age groups $\left(\chi^{2}=8.85, p=.012\right)$. Overall, $33.3 \%$ had been screened for bone density status previously, 54.5\% in Peri-M, and $42.9 \%$ in Post-M, which was statistically significant $\left(\chi^{2}=15.31, p<.001\right.$; Table 1).
Regarding health care services, $23.8 \%$ reported they heard about their own 'brittle bones' from HCPs $\left(\chi^{2}=3.30, p=.192\right)$ and $17.5 \%$ were recommended for screening to determine their bone status $\left(\chi^{2}=3.96, p=.138\right)$. There were no significant differences between age groups (Table 1 ).

Table 1. Demographic Characteristics of Participants $(N=63)$

\begin{tabular}{|c|c|c|c|c|c|c|c|c|c|}
\hline & \multirow[b]{2}{*}{$n$} & \multirow[b]{2}{*}{$(\%)$} & \multicolumn{2}{|c|}{$\begin{array}{c}\text { Pre-M } \\
\text { Age: } 25-35 y r s\end{array}$} & \multicolumn{2}{|c|}{$\begin{array}{c}\text { Peri-M } \\
\text { Age: } 45-55 y r s\end{array}$} & \multicolumn{2}{|c|}{$\begin{array}{c}\text { Post-M } \\
\text { Age: } 65+\end{array}$} & \multirow[b]{2}{*}{$\chi^{2}$} \\
\hline & & & $n=20$ & $(\%)$ & $n=22$ & $(\%)$ & $n=21$ & $(\%)$ & \\
\hline Age (Years) & 63 & $(51.7)$ & 30.6 & (3.3) & 50.97 & $(2.5)$ & 72.7 & (7.0) & $415.95 \ddagger$ \\
\hline Currently Married & 42 & $(67.7)$ & 13 & $(68.4)$ & 20 & $(90.9)$ & 9 & $(42.9)$ & $11.36 \dagger$ \\
\hline Employed & 19 & $(30.2)$ & 6 & $(30.0)$ & 13 & $(59.1)$ & 0 & $(0.0)$ & $17.81+$ \\
\hline \multicolumn{10}{|l|}{ Family Income: } \\
\hline$<\$ 30,000$ & 32 & $(51.6)$ & 7 & $(36.8)$ & 7 & $(36.8)$ & 18 & $(85.7)$ & \\
\hline$<\$ 60,000$ & 7 & $(11.3)$ & 2 & $(10.5)$ & 4 & $(18.2)$ & & $(4.8)$ & $15.46 \dagger$ \\
\hline$\geq \$ 60,000$ & 23 & $(37.1)$ & 10 & $(52.6)$ & 11 & $(50.0)$ & & (9.5) & \\
\hline Living Alone & 7 & $(11.1)$ & 1 & $(5.0)$ & 0 & $(0.0)$ & 6 & $(28.6)$ & $9.99 \dagger$ \\
\hline Have Health Insurance & 37 & $(58.7)$ & 11 & $(55.0)$ & 9 & $(40.9)$ & 17 & $(81.0)$ & $7.28 *$ \\
\hline Have a Primary Care Provider & 20 & $(31.7)$ & 7 & $(35.0)$ & 5 & $(22.7)$ & 8 & $(38.1)$ & 1.314 \\
\hline Aware at High Risk of Developing Osteoporosis & 22 & $(34.9)$ & 5 & $(25.0)$ & 13 & $(59.1)$ & & $(19.0)$ & $8.85 *$ \\
\hline Screened Bone Status & 21 & $(33.3)$ & 0 & $(0.0)$ & 12 & $(54.5)$ & 9 & $(42.9)$ & $15.31 \ddagger$ \\
\hline Heard About Your Brittle Bones & 15 & $(23.8)$ & 2 & $(10.0)$ & 6 & $(27.3)$ & 7 & $(33.3)$ & 3.30 \\
\hline Told to Screen Bone Health & 11 & $(17.5)$ & 1 & $(5.0)$ & 4 & $(18.2)$ & & $(28.6)$ & $3.91 * *$ \\
\hline \multicolumn{10}{|l|}{ BMD Level (Femur Neck): } \\
\hline Normal & 24 & $(38.1)$ & 11 & $(55.0)$ & 10 & $(45.5)$ & & (14.3) & \\
\hline Lower Than Normal & 30 & $(47.6)$ & 9 & $(45.0)$ & 10 & $(45.5)$ & 11 & $(52.4)$ & $13.70 \dagger$ \\
\hline Osteoporosis & 9 & $(14.3)$ & 0 & $(0.0)$ & 2 & $(9.0)$ & & $(33.3)$ & \\
\hline
\end{tabular}

Note. Pre-M = Pre-Menopause, Peri-M = Peri-Menopause, Post-M = Post-Menopause; ${ }^{*} p<.05, \dagger p<.01, \dagger p<.001, * *$ Fisher's Exact Test value

From the BMD screening, $14.3 \%$ of participants had osteoporosis $(9.0 \%, 33.3 \%$ in Peri-M and Post-M, respectively); $47.6 \%$ had low BMD levels which ranged between $45-52 \%$ across all age groups. This was statistically significant $\left(\chi^{2}=13.70, p=.008\right)$. As shown in Figure 1, BMD levels in the Post-M group significantly declined. In Figure 2, 68\% of the Peri-M group (aged 45-55 years) were aware of risks of their osteoporosis and $57.0 \%$ had been screened for BMD previously, while $24.0 \%$ of the Post-M groups were aware of their risks and $43.0 \%$ had a history of BMD screening.

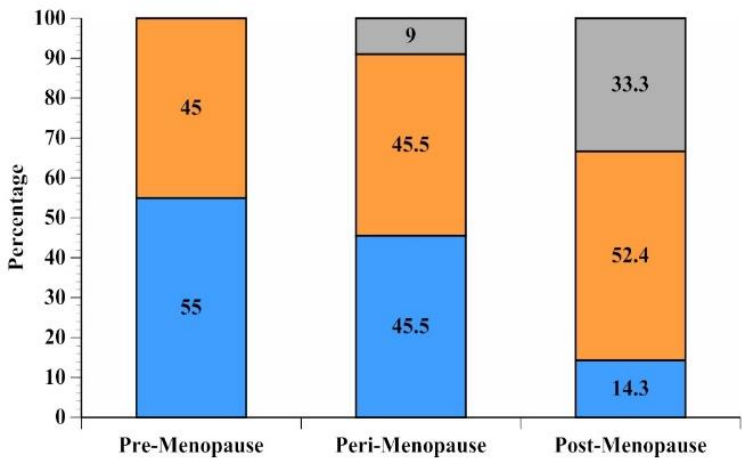

Figure 1. Level of bone density by age group; $\square$ Normal; Lower than Normal; $\square$ Osteoporosis. 


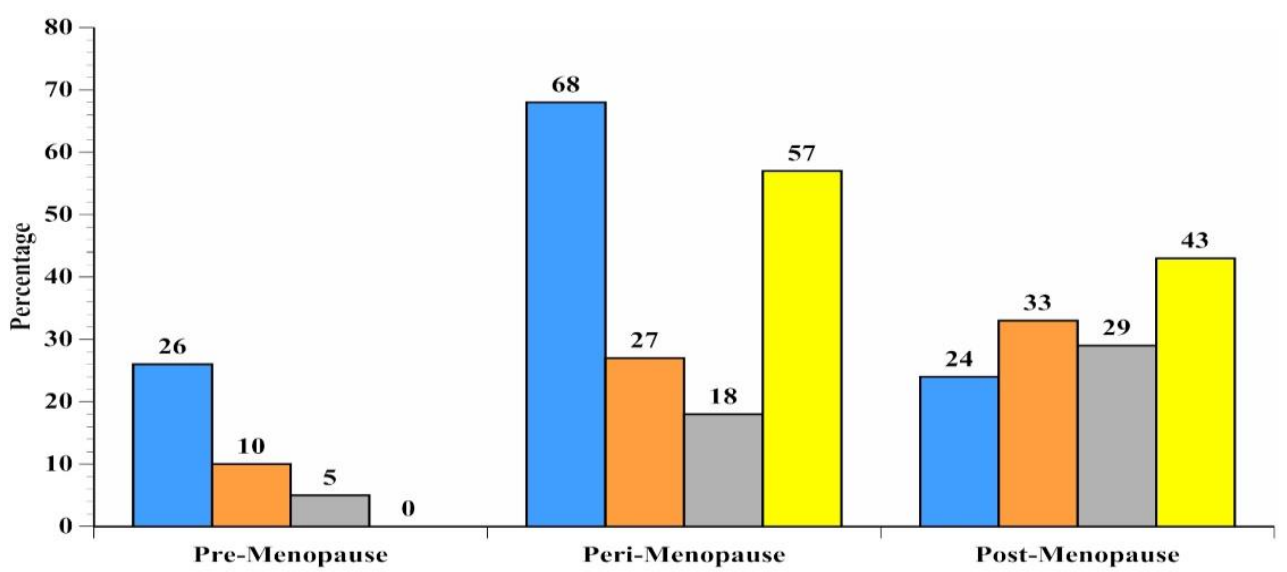

Figure 2. Level of bone density by age group. Note. ${ }^{*} p<.05$; $\square$ Perceived Risk (High)*; $\square$ Heard about Brittle Bones; $\square$ Was told to Screen; $\square$ Screened.

\section{Comparison of Awareness, Screening His- tory and Health Care Services by BMD Findings}

The awareness of a high risk of osteoporosis and the history of BMD screening were not significantly different between BMD levels (normal versus lower than normal; $p>.05$; Table 2). Further-more, those who were told from HCPs regarding their own osteoporosis, $25.6 \%$ were in the lower BMD and $20.8 \%$ were in the normal BMD groups $\left(\chi^{2}=1.21, p\right.$ $=.546)$, with a recommendation of screening not significantly different between BMD levels (normal versus low; $p>.05$; Table 2 and Figure 3 ).

Table 2. Awareness, Care Service, and Screening of Bone Status by Bone Status

\begin{tabular}{|c|c|c|c|c|c|c|c|c|}
\hline & \multirow[b]{2}{*}{$n$} & \multirow[b]{2}{*}{$(\%)$} & \multicolumn{2}{|c|}{ Normal } & \multicolumn{2}{|c|}{ Lower Than Normal } & \multirow[b]{2}{*}{$\chi^{2}$} & \multirow[b]{2}{*}{$p$} \\
\hline & & & $n=24$ & $(\%)$ & $n=39$ & $(\%)$ & & \\
\hline Aware at High Risk of Developing Osteoporosis & 22 & $(34.9)$ & 10 & $(41.7)$ & 12 & $(30.8)$ & 0.776 & 0.378 \\
\hline Screened Bone Status & 21 & $(33.3)$ & 7 & $(29.2)$ & 14 & $(35.9)$ & 0.303 & 0.784 \\
\hline Heard about your Brittle Bones & 15 & $(23.8)$ & 5 & $(20.8)$ & 10 & $(25.6)$ & 1.210 & 0.546 \\
\hline Told to Screen Bone Health & 11 & $(17.5)$ & 4 & $(16.7)$ & 7 & $(17.9)$ & $0.017 * *$ & 0.590 \\
\hline
\end{tabular}

Note. **Fisher's Exact Test value

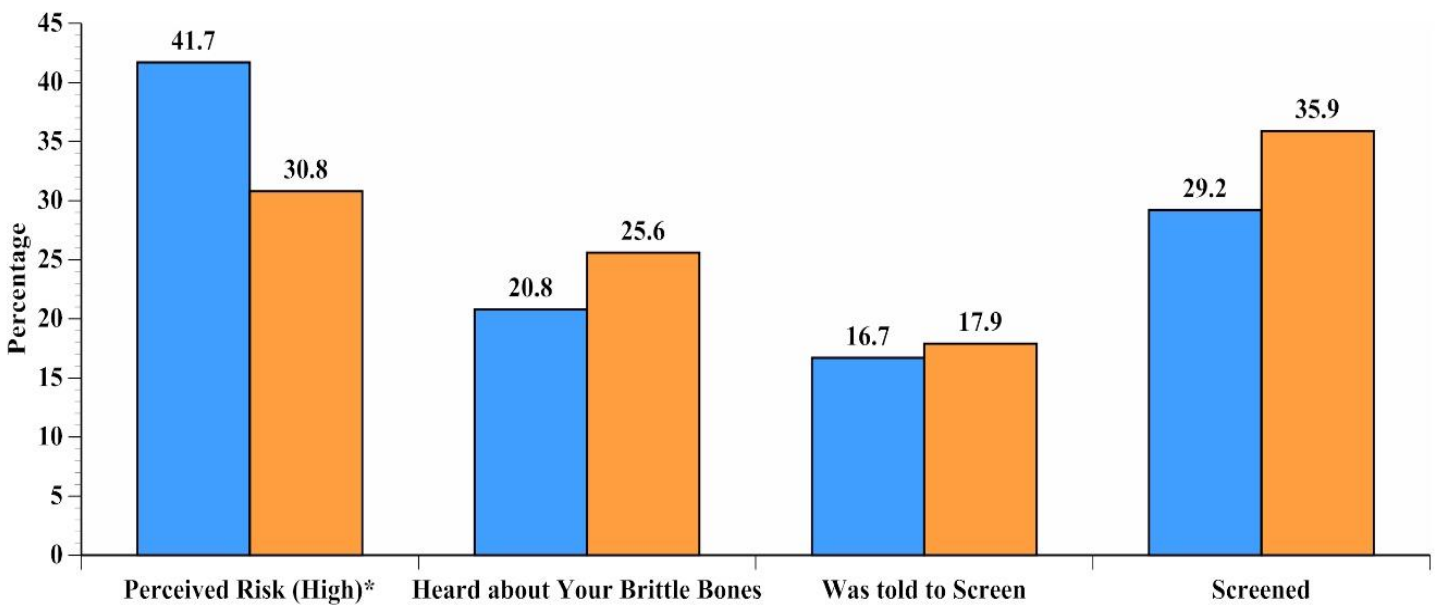

Figure 3. Perception, Health Services, and Screening by Bone Mineral Density; $\square$ Normal; $\square$ Lower than Normal. 
Comparison of Awareness, Screening History, and Information Received by Health Insurance and Primary $\mathrm{HCP}$

Regarding the awareness by health insurance coverage and having a primary $\mathrm{HCP}, 38.5 \%$ of $\mathrm{KA}$ women without health insurance were aware of their own risks of osteoporosis compared to $35.3 \%$ in those who had health insurance but no primary $\mathrm{HCP}$, and $30 \%$ of those with health insurance and with a primary HCP. No significant differences among groups were found $(p>.05$; Table 3$)$.

Table 3. Awareness, Care Service, and Screening of Bone Status by Health Insurance

\begin{tabular}{|c|c|c|c|c|c|c|c|c|c|}
\hline & \multirow[b]{2}{*}{$n=63(\%)$} & \multicolumn{2}{|c|}{$\begin{array}{c}\text { No insurance \& } \\
\text { no PCP }\end{array}$} & \multicolumn{2}{|c|}{$\begin{array}{c}\text { Insurance } \\
\text { but no PCP }\end{array}$} & \multicolumn{2}{|c|}{$\begin{array}{c}\text { Insurance \& } \\
\text { PCP }\end{array}$} & \multirow[b]{2}{*}{$\chi^{2}$} & \multirow[b]{2}{*}{$p$} \\
\hline & & $n=17$ & $(\%)$ & $n=17$ & $(\%)$ & $n=20$ & $(\%)$ & & \\
\hline Aware at High Risk of Developing Osteoporosis & $22(34.9)$ & 10 & $(38.5)$ & 6 & $(35.3)$ & 6 & $(30.0)$ & 0.358 & 0.836 \\
\hline Heard about your Brittle Bones & $15(23.8)$ & 8 & $(30.0)$ & 3 & $(17.6)$ & 4 & $(26.7)$ & $1.120 * *$ & 0.604 \\
\hline Told to Screen Bone Health & $11(17.5)$ & 2 & $(7.7)$ & 4 & $(23.5)$ & 5 & $(25.0)$ & $3.130 * *$ & 0.214 \\
\hline Screened Bone Status & $21(33.3)$ & 8 & $(30.8)$ & 6 & $(35.3)$ & 7 & $(35.0)$ & 0.131 & 0.936 \\
\hline
\end{tabular}

Note. $\mathrm{PCP}=$ Primary Care Provider; **Fisher's Exact Test value

Overall, $33.3 \%$ of KA women had a history of BMD screening. No differences in BMD history among groups having health insurance or having a primary HCP group were found. The information received from the $\mathrm{HCP}$ regarding their osteoporosis and recommended bone screening was not significantly different between the groups with and without health insurance or a primary HCP (Figure 4).

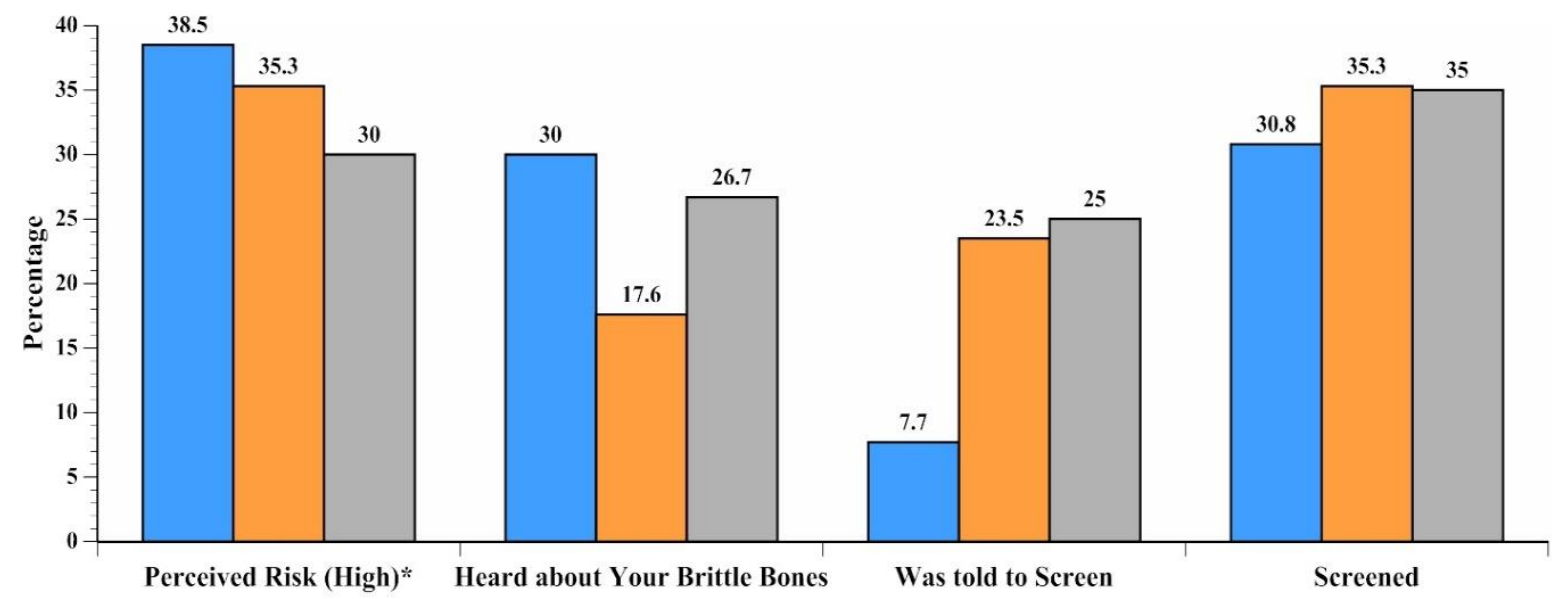

Figure 4. Perception, Health Services, and Screening by Health Insurance and PCP; $\square$ No Health Insurance; $\square$ Health Insurance, No Primary Care Provider; $\square$ Health Insurance with Primary Care Provider.

\section{Discussion}

KA women's BMD findings showed significant age-related differences. Although low BMD levels during the post-menopausal stage were consistent with the other ethnic results, the prevalence of osteoporosis of KA women (20.9\%) was much higher than White, Hispanic, and Black women (6$17 \%$ ) in the United States (Kanis et al., 2008; National
Committee for Quality Assurance, 2015; Wright et al., 2014) but lower (39-40\%) than women in Korea (Kim et al., 2012; Kim, Kim, \& Cho, 2015). The BMD screening rates in the Post-M group (65 years and older) were far below the national rate of $42.9 \%$ versus $73.6 \%$, respectively (National Committee for Quality Assurance, 2015). These findings represent a challenge to meet the target of Healthy People 2020. 
The current findings indicate a serious disparity in health care coverage of KA women when compared to the national data. In 2013, uninsured health insurance rates in Asian-Americans were $13.8 \%$ compared to $41.3 \%$ of KA women in the current study (Smith \& Medalia, 2015). Almost half of the Pre-M and Peri-M groups had no health insurance that might result from low employment. Furthermore, only $32 \%$ of KA women in the current study had a usual primary HCP, which was much lower than the national average of $77.3 \%$ in 2011 and other studies using KA women (Eun, Lee, Kim, \& Fogg, 2009; U.S. Department of Health and Human Services, 2014). Even though the sample of this study was a convenience selection, the low rate of coverage of health insurance or no usual primary HCP are significant barriers for regular reliable access to health services. Studies with a large sample can clarify the differences of the importance of insurance coverage.

Regarding awareness of their own risks of osteoporosis, overall low perception of their own bone health was consistent with the literature conducted with other ethnic groups in the United States or Koreans in Korea (Carlsson \& Johnson, 2004; Gerend, Erchull, Aiken, \& Maner, 2006; Kim et al, 2012; Tan et al., 2009). The Peri-M (aged 45-55 years) women's awareness was higher $(59 \%)$ than the Post-M (age $65+, 19.0 \%$ ) women, so the screening behaviors were inconsistent with the studies conducted in Korea regarding awareness of osteoporosis of women aged 50 years or older in that they did not differ with age or bone condition (Kim et al., 2012; Shin, Kang, Lee, \& Park, 2014). This can be explained as the transitional menopausal status in the Peri-M group might have taken it upon themselves to seek screening. Also, the KA women's awareness regarding their own risks of osteoporosis was quite low and inconsistent with the prevalence of low BMD status, screening behaviors, and information received from their HCPs. This finding can be explained by the realization that perceived susceptibility (one's opinion of chances of developing a condition) in Korean immigrants was low, while their health motivation and perceived severity (one's opinion of how serious a condition and its consequences are) were high (Carlsson \& Johnson, 2004).

The prevalence rate of low bone mass (osteoporosis or lower than normal DXA test) was higher than the rates of their awareness and screening behaviors showed. Even though the result was not statistically significant between groups, the discrepancies between the awareness and screening history or BMD findings imply that KA women did not know the results or the meaning of the previous screenings or tests. Furthermore, the KA women's knowledge or healthseeking behaviors did not seem to originate from the health care system or services, because the rate of previous bone screening in Peri-M group (54.5\%) exceeded the rates of having health insurance $(40.9 \%)$ and having a primary HCP $(31.7 \%)$. Some of the previous DXA screenings of KA women were not covered by their own health insurance. Education for bone health should be delivered in both public and private clinical sites for KA women to have accurate knowledge, which can be articulated by appropriate health advice through health care providers.

Only $17.9 \%$ of KA women with low BMD were told to obtain screening for bone status from their HCPs. Even though $81.0 \%$ of the Post-M group had health insurance coverage and $33.0 \%$ had osteoporosis, a low number of them $(28.6 \%)$ were advised to obtain screening for BMD from their HCP. These findings indicate that KA women's health-seeking behaviors for bone health were not based on their health insurance and perhaps not emphasized by a HCP. Even though the KA women's bone conditions were frequently worse than those of other ethnic groups (Kim et al., 2012; Tan et al., 2009), their perceptions and behaviors seemed to be sporadic and did not satisfy the requirements of appropriate care management.

In the Behavioral Model, the perception (awareness) and their health behaviors (screening) were hypothesized to be influenced by use of the health services in the health care delivery system. This current finding did not support the hypothesis of the study, which is inconsistent with other studies of those who had primary care providers and better health behaviors and screening (Lee et al., 2012). The current findings included outcomes which did not explain the model because the majority of KA women did not have both health insurance and primary care providers. The recommendations are as follows: (a) KA women should be included in the health care delivery system of the country to gain access to health services and have a regular PCP, and (b) studies are needed to identify what guided KA women's perception and healthseeking behaviors as well as the cultural characteristics of health care delivery services. The current study used Anderson's Behavioral Model for the first time to explain health care service usage and osteoporosis among KA women; therefore, studies testing the model need to be conducted again after improving the coverage of health insurance.

To reduce the disparities and discrepancies of bone conditions and perceptions from this study, the empirical recommendation is to educate and encourage KA women to have health insurance coverage with private or public health care which is available through the Affordable Care Act. With adequate health insurance coverage, establishing a primary HCP would be more likely to happen. With a specific primary HCP, KA women would be more likely to receive the benefits of regular check-ups, early detection of disease, and appropriate 
management to coordinate with other health problems and treatment regimens.

Public health education about bone health should be delivered through KA communities such as KA associations, religious organizations, and community events to disseminate this knowledge, and encourage health-seeking behaviors and appropriate management. Future studies identifying the source of KA women's perceptions and health-seeking behaviors could help to further understand the KA women's bone health status and development of necessary intervention strategies.

\section{Conclusion}

The study shows that KA women are one of the most underserved groups in the U.S health care system with low rates of insurance coverage and a low likelihood of having a primary HCP. There was an age difference in perception of the risks of osteoporosis, bone strength, and screening behaviors but inconsistencies existed among the concepts. To improve the KA women's bone health and reduce the disparities among ethnic groups the following actions are recommended: (a) accessibility to health care services should be improved to provide better opportunities for education, medical intervention, and appropriate resources; and (b) public education for bone health and disease prevention should be made more easily accessible.

\section{Funding}

This research study was supported by the San Diego State University Grant Program (SDSURF \#242381).

\section{References}

Agency for Healthcare Research and Quality. (2011, October). Disparities in healthcare quality among racial and ethnic minority groups: Selected findings from the 2010 National Healthcare Quality and Disparities Report (Publication No. \# 11-0005-3$\mathrm{EF})$. Rockville, MD. Retrieved from http://www.ahrq.gov/research/findings/nhqrdr/ nhqrdr10/minority.html

Anderson, R. (2008). National health surveys and the behavioral model of health services use. Medical Care, 46, 647-653. doi:10.1097/MLR.0b013e31817a835d

Andersen, R, M. (1995). Revisiting the behavioral model and access to medical care: Does it matter? Journal of Health and Social Behavior, 36, 1-10.

Babitsch, B., Gohl, D., \& von Lengerke, T. (2012). Re-visiting Andersen's Behavioral Model of Health Services Use: A systematic review of studies from 1998-2011. Psychosocial Medicine, 9, Doc11. doi:10.3205/psm000089
Carlsson, L., \& Johnson, C. S. (2004). Osteoporosis health beliefs and practices among Korean immigrants in Nova Scotia. Journal of Immigrant Health, 6, 93100. doi:10.1023/B:JOIH.0000019169.41271.f5

Chen, L. H., Warner, M., Fingerhut, L., \& Makuc, D. (2009). Injury episodes and circumstances: National Health Interview Survey, 1997-2007. Vital and Health Statics, 10(241), 1-55. Retrieved from www.cdc.gov/nchs/data/series/sr_10/sr10_241.pdf

Centers for Medicare \& Medicaid Services. (2016). Glossary: Primary care provider. U.S. Centers for Medicare \& Medicaid Services. Baltimore, MD. Retrieved from https://www.healthcare.gov/glossary/primary-care-provider/

Cramer, D. W., \& Xu, H. (1996). Predicting age at menopause. Maturitas, 23, 319-326. doi:10.1016/ 0378-5122(96)00992-9

Eun, Y., Lee, E. E., Kim, M. J., \& Fogg, L. (2009). Breast cancer screening beliefs among older Korean American women. Journal of Gerontological Nursing, 35(9), 40-50. doi:10.3928/0098913420090731-09

Gerend, M. A., Erchull, M. J., Aiken, L. S., \& Maner, J. K. (2006). Reasons and risk: Factors underlying women's perceptions of susceptibility to osteoporosis. Maturitas, 55, 227-237.

He, W., Sengupta, M., Velkoff , V.A., \& DeBarros, K. A. (2005). 65+ in the United States: 2005. Washington, DC: U.S. Government Printing Office.

Hertzog, M. A. (2008). Considerations in determining sample size for pilot studies. Research in Nursing and Health, 31, 180-191. doi:10.1002/nur.20247

Kanis, J. A., McCloskey, E. V., Johansson, H., Oden, A., Melton, L. J. r., \& Khaltaev, N. (2008). A reference standard for the description of osteoporosis. Bone, 42, 467-475. doi:410.1016 /j.bone.2007. 1011.1001.

Kim, K. H., Lee, K., Ko, Y. J., Kim, S. J., Oh, S. I., Durrance, D. Y., . . Park, S. M. (2012). Prevalence, awareness, and treatment of osteoporosis among Korean women: The Fourth Korea National Health and Nutrition Examination Survey. Bone, 50(5), 10391047. doi:10.1016/j.bone.2012.02.007

Kim, Y., Kim, J. H., \& Cho, D. S. (2015). Gender difference in osteoporosis prevalence, awareness and treatment: Based on the Korea National Health and $\mathrm{Nu}-$ trition Examination Survey 2008 2011. Journal of Korean Academy of Nursing, 45, 293-305. doi:10.4040/jkan.2015.45.2.293

Lee, S., \& Jang, Y. (2016). Factors Associated with Willingness to Use Mental Health Services in Korean Immigrants. Social Work in Public Health, 31, 196-203. doi:10.1080/19371918.2015.1125319

Lee, Y. S., Hofstetter, C. R., Irvin, V. L., Kang, S., Chhay, D., Reyes, W. D., \& Hovell, M. F. (2012). Korean American women's preventive health care practices: Stratified samples in California, USA. Health Care for Women International, 33, 422439. doi:10.1080/07399332.2011.603869

Mazzuoli, G., Acca, M., Pisani, D., Diacinti, D., Scarda, A., Scarnecchia, L., ... Manfredi, G. (2000). Annual 
skeletal balance and metabolic bone marker changes in healthy early postmenopausal women: Results of a prospective study. Bone, 26(4), 381386. doi:10.1016/s8756-3282(00)00242-8

National Committee for Quality Assurance. (2015). NCQA's 2014 State of Health Care Quality Report: Healthcare Effectiveness Data and Information Set (HEDIS). Retrieved from http://www.ncqa.org /report-cards/health-plans/state-of-health-carequality/2015-table-of-contents/osteoporosis

National Institutes of Health. (2015). Osteoporosis: Overview. Retrieved from Retrieved from http://www.niams.nih.gov/Health_Info/Bone/Osteoporosis/overview.asp

Shin, H. Y., Kang, H. C., Lee, K., \& Park, S. M. (2014). Association between the awareness of osteoporosis and the quality of care for bone health among Korean women with osteoporosis. BMC Musculoskeletal Disorders, 15, 334. doi:10.1186/14712474-15-334

Smith, J. C., \& Medalia, C. (2015). Health insurance coverage in the United States: 2014, Current population reports (pp. 60-250). Washington, DC: U.S. Government Printing Office.

Tan, S., Ji, L., Tsai, J., Eng, J., Ko, H. J., Yau, A., ... Edwards, B. J. (2009). Greater osteoporosis educational outreach is desirable among Chinese immigrants in Chinatown, Chicago. Osteoporosis International, 20, 1517-1522. doi:10.1007/ s00198-008-0828-3

U.S. Census Bureau (2012). The Asian population in theUnited States: Results from the 2010 Census. Racial Statistics Population Division, U.S. Census
Bureau. Retrieved from https://www.ssa.gov/ people/aapi/materials/pdfs/2010census-data.pdf

U.S. Department of Health and Human Services. (2004). A report of the Surgeon General: Bone Health and Osteoporosis. Rockville, MD: U.S. Department of Health and Human Services, Office of the Surgeon General.

U.S. Department of Health and Human Services. (2014). Healthy People 2020 leading health indicators: Access to health services. Retrieved from https://www.healthypeople.gov/sites/default/files/HP2020_LHI_Acc_Hlth_Svcs_0.pdf

U.S. Department of Health and Human Services. (2015). Healthy People 2020 framework: The vision, mission, and goals of Healthy People 2020. Retrieved from https://www.healthypeople.gov/ sites/default/files/HP2020Framework.pdf

World Health Organization. (1994). Assessment of fracture risk and its application to screening for postmenopausal osteoporosis. Report of WHO Study group. WHO Technical Report Series, vol. 843. Geneva: WHO.

World Health Organization. (2004). WHO Scientific group on the assessment of osteoporosis at primary health care level. Retrieved www.who.int/chp/ topics/ Osteoporosis.pdf

Wright, N. C., Looker, A. C., Saag, K. G., Curtis, J. R., Delzell, E. S., Randall, S., \& Dawson-Hughes, B. (2014). The recent prevalence of osteoporosis and low bone mass in the United States based on bone mineral density at the femoral neck or lumbar spine. Journal of Bone and Mineral Research, 29, 2520-2526. doi:10.1002/jbmr.2269 